\title{
Teachers' Goal Orientation Profiles and Participation in Professional Development Activities
}

\author{
Eva M. Kunst ${ }^{1}$ (D) Marianne van Woerkom ${ }^{1}$. \\ Rob F. Poell ${ }^{1}$
}

Received: 20 June 2016 / Accepted: 4 May 2017 /

Published online: 11 May 2017

(C) The Author(s) 2017. This article is an open access publication

\begin{abstract}
Participation in professional development activities is important for teachers to continuously improve their knowledge and skills. However, teachers differ in their attitude towards learning activities. This paper examined how different goal orientation profiles are related to participation in professional development activities (acquiring information and asking feedback). To this end, we conducted latent profile analysis based on a sample of 984 teachers in vocational education. Five profiles were identified: diffuse $(50.1 \%)$, moderate learning $(12.3 \%)$, high avoidance $(10.9 \%)$, performance oriented $(15.9 \%)$ and success oriented $(10.7 \%)$. Furthermore, means of acquiring information and asking feedback from teachers were compared across the profiles. Teachers with a success-oriented profile (high learning and performance approach goals) scored significantly higher while teachers with a high-avoidance profile scored significantly lower on asking for feedback and acquiring information. Exploration of background characteristics indicated that age, gender and work experience outside education were related to the goal orientation profiles. Our findings show that goal orientation profiles can be used to explain individual differences in teachers' propensity to engage in professional development activities.
\end{abstract}

Keywords Goal orientation · Teachers · Asking feedback · Information acquisition · Latent profile analysis $\cdot$ Professional development

Participation in professional development activities is important for teachers to continuously improve their knowledge and skills. However, research shows that teachers differ strongly in how actively they engage in formal and informal learning activities

Eva M. Kunst

e.m.kunst@tilburguniversity.edu

1 Department of Human Resource Studies, Tilburg University, PO Box 90153, Tilburg,

The Netherlands 
such as seeking information, participation in workshops in- or outside the school, and asking for feedback (Kwakman, 2003; Opfer \& Pedder, 2011; Runhaar, Sanders, \& Yang, 2010; Lohman, 2005). It is likely that teachers' motivation to participate in professional development activities is related to their goal orientation (Nitsche, Dickhäuser, Fasching, \& Dresel, 2013; Van Eekelen, Vermunt, \& Boshuizen, 2006).

Achievement goal theory (Ames \& Ames, 1984; Dweck, 1986, 1990; Nicholls, 1984) posits that individuals can strive for learning goals, performance approach goals and performance avoidance goals (VandeWalle, 1997). Learning goals refer to the individual's intention to develop competencies, knowledge or skills. Individuals with a learning goal orientation view challenging tasks as an opportunity for learning, and interpret failures as a starting point for learning (Dweck, 1990). Performance approach and avoidance goals refer to the tendency to be concerned with positive confirmation of demonstrated behavior from others. The relative standard that performance oriented individuals are comparing themselves with can include both external factors (such as colleagues, performance norms) and internalized standards (for example, individual expectations, or previous performance levels) (Van Yperen, 2006). Performance approach goals are associated with demonstrating high performance to others, whereas performance avoidance goals are characterized by avoiding the demonstration of incompetence (VandeWalle, 1997).

Although many authors assume that individuals have a single dominant goal orientation, the multiple goal orientation perspective is more and more accepted in research (Payne, Youngcourt, \& Beaubien, 2007) and several qualitative studies give vivid descriptions of students pursuing multiple goals (Lee \& Anderson, 1993; Levy, Kaplan, \& Patrick, 2004). Coexistence of multiple goal orientations builds on the interactive goal hypothesis proposed by Barron and Harackiewicz (2001) which is based on the idea that all three goal orientations are represented within a person, but that the level of goal orientations can vary between persons depending on personality and situational cues (Luo, Paris, Hogan, \& Luo, 2011). Barron and Harackiewicz (2001) posit that the interactive effect of different goal orientations will potentially explain more variance in performance and learning compared to the additive effects. Different combinations of goal orientations may boost each other or work as a buffer to diminish negative effects of specific goal orientations. For example, a teacher that scores high on both the learning and performance-avoidance goal orientation is eager to try out new tasks at work and at the same time concerned with the negative judgement of others if these innovations would fail. In this case the learning goal orientation may function as a buffer and reduce the negative impact of the performance-avoidance goal orientation, possibly resulting in a tendency to start experimenting with small educational innovations with a high chance of success. Studies investigating the additive effects of goal orientations often take a variable-centered approach (Pastor, Barron, Miller, \& Davis, 2007), using multiple regression analysis or correlational analysis to study the associations between single goal orientations and various outcomes (i.e. learning attitude or task performance) (Pastor et al., 2007). However, the variablecentered approach does not take into account mutually occurring goal orientations within one person. A person-centered approach facilitates the study of multiple goal orientations that coexist within a person. Latent profile analysis is a person-centered type of analysis, which identifies subgroups of individuals with similar characteristics on multiple predictors (Pastor et al., 2007). This data-driven clustering technique can be 
used by researchers who are interested in multiplicative effects instead of only additive, direct effects (Merz \& Roesch, 2011).

The purpose of the current study is to explore goal orientation profiles of teachers in Vocational and Educational Training (VET) colleges and to advance our understanding of the relationship between goal orientation profiles and professional development activities. Teachers in Dutch VET colleges have been confronted with a major educational reform in the recent years: the implementation of Competence Based Education (CBE). The central aims of CBE are teaching students in an authentic context similar to their future workplace and preparing students for life-long learning and independent craftsmanship (Biemans et al., 2009). To foster this innovation and strengthen the link with practice, the teaching staff of VET colleges is composed of teachers from different subjects (vocational or general subjects such as languages and mathematics) that work together in multidisciplinary teams to successfully organize vocational education programs (Oude Groote Beverborg, 2015). Ongoing involvement in professional development activities, such as acquiring information, asking colleagues for feedback, or experimenting with new teaching practices contributes to the successful implementation of CBE and other educational innovations (Stoll, Bolam, McMahon, Wallace, \& Thomas, 2006).

This study provides a contribution to the literature on goal orientations by exploring goal orientation profiles in the work domain, specifically for teachers. This is important because current studies in the work context mainly focus on linear relationships between single goal orientations, thereby neglecting the possibility of coexistence of different goal orientations. Until now, no studies have investigated goal orientation profiles of employees in the context of work and most studies focus on students' goal orientation (Luo et al., 2011; Pastor et al., 2007; Schwinger, Steinmayr, \& Spinath, 2012; Schwinger \& Wild, 2012; Tuominen-Soini, Salmela-Aro, \& Niemivirta, 2008, 2011, 2012; Jansen in de Wal, Hornstra, Prins, Peetsma, \& van der Veen, 2016; Pulkka \& Niemivirta, 2013; Kolić-Vehovec, Rončević, \& Bajšanski, 2008; Shim \& Finch, 2014). Because the educational context differs from the work context in the explicit attention to learning and the assessment of performance, the outcomes of these studies cannot be translated one-on-one to a work context. Because the educational context differs from the work context in the explicit attention to learning and the assessment of performance, the outcomes of these studies cannot be translated one-on-one to the work context. Workplace learning of teachers is different compared to students learning at school; whereas the school context has a dominant and explicit focus on learning and development (Tynjälä, 2008) learning in the context of work is mostly informal, unintentional and unplanned (Eraut, 2004; Tynjälä, 2008). Therefore, our study aims to investigate goal orientation profiles that may explain to what extent teachers engage in professional development activities and how background characteristics (age, gender, previous work experience) are associated with goal orientation profiles. Furthermore, this study contributes to the literature on professional development of teachers by connecting goal orientation profiles to information acquisition and asking for feedback. Previous studies reported a positive relationship between a learning goal orientation and a performance-approach goal orientation on the one hand and asking for feedback on the other hand (Janssen \& Prins, 2007; Poortvliet, Janssen, Van Yperen, \& Van de Vliert, 2007). However, these previous studies did not take into account the fact that different goal orientations coexist within individuals and that a specific combination of 
goal orientation can strengthen or buffer the effect of single goal orientations on professional development. Therefore, by addressing the role of goal orientation profiles in professional development, we extend the current knowledge on teachers' motivation for professional development (Butler, 2007). School leaders may use this knowledge to develop professional development policies that aim to encourage the participation of specific groups of teachers in professional development activities.

\section{Theoretical Framework}

\section{Goal Orientation in the Work Domain}

In the majority of studies including learning goal orientation, positive associations with learning attitude and task performance were found (for a detailed metaanalysis on samples of adults in work and occupational settings see Payne et al. (2007)). Studies that are based on samples of teachers (Chughtai \& Buckley, 2010; Runhaar et al., 2010) found positive associations between a learning goal orientation and feedback seeking behavior of teachers. When a learning goal orientation is adopted, environmental cues such as positive and negative feedback and experimenting with new ways of working are considered relevant to improve skills and not as a judgement of performance (VandeWalle, 2004). Teachers with a high learning goal orientation invest more in their professional development (Runhaar et al., 2010) and have higher levels of self-efficacy (Butler, 2007; Runhaar et al., 2010; Schiefele \& Schaffner, 2015) and pro-active behavior (Zhang, Law, \& Lin, 2016). Moreover, various studies have found that teachers with a learning goal orientation are more supportive towards their students, using learning goal-oriented instructional practices (Butler \& Shibaz, 2008; Retelsdorf, Butler, Streblow, \& Schiefele, 2010). Studies including performance approach goals reported ambivalent results as becomes evident from the meta-analysis of Payne et al. (2007). Believe in stable and fixed traits (entity theory) were positively related to the performance approach goal orientation, whereas self-esteem and self-efficacy were negatively related to the performance approach goal orientation. Moreover, the outcomes learning, task performance, and job performance were unrelated to the performance-approach goal orientation. More recent studies in the teacher domain found that a performance-approach goal orientation was positively associated with work engagement (Han, Yin, \& Wang, 2016; Kunsting, Neuber, \& Lipowsky, 2016; Parker, Martin, Colmar, \& Liem, 2012; Skaalvik \& Skaalvik, 2013) but that teachers with higher levels of performance approach goals also perceived more occupational strain (Nitsche et al., 2013) and demonstrate lower-levels of pro-active work behavior (Zhang et al., 2016). Performance avoidance goals were mostly found to be associated with more negative outcomes (Payne et al., 2007). Individuals with a high level of performance avoidance goals perceive their skill set as finite and regard environmental cues as threats rather than opportunities for development (VandeWalle, 2004). This is detrimental for learning since opportunities, like asking support from colleagues and searching for new information, are not fully used. This was supported by the meta-analysis of Payne et al. (2007). The performance-avoidance goal orientation was negatively 
associated with self-esteem, feedback seeking behavior, and task performance, and positively associated with anxiety. This is in line with Parker et al. (2012) who found that teachers with high levels of performance avoidance demonstrate selfhandicapping behavior such as procrastination and unrealistic goal setting.

Research applying goal orientation profiles has until now been limited to the context of education and is exclusively based on samples of students. A literature search on studies of goal orientation profiles resulted in eleven studies all based on student samples. The number of goal orientation profiles found ranged between three and six. Two studies found three goal orientation profiles in samples of primary school students (Jansen in de Wal et al., 2016; Schwinger \& Wild, 2012). Jansen in de Wal et al. (2016) distinguished a high multiple goal orientation profile (high scores on all goal orientations), a diffuse goal orientation profile (average scores on all goal orientations) and a performance oriented profile (with high scores on both performance goals). Schwinger and Wild (2012) also identified the multiple goals and diffuse profile but identified a high learning goal orientation profile instead of the approach oriented profile. A four-profile solution was found in six studies (Luo et al., 2011; Schwinger, Steinmayr, \& Spinath, 2016; Tapola \& Niemivirta, 2008; Tuominen-Soini et al., 2011, 2012; Wang, Morin, Liu, \& Chian, 2016), including a high performance, high-avoidance and a success-oriented profile (combining high performance goals and high learning goals) (Tuominen-Soini et al., 2011, 2012). Other combinations found in four profile solutions were diffuse, multiple goals, all high goals and disengaged (all low goals) (Wang et al., 2016); diffuse, approach oriented, moderate learning and success-oriented (Luo et al., 2011); and high-avoidance, success-oriented, approach oriented and high learning oriented (Tapola \& Niemivirta, 2008). Pastor et al. (2007) identified five goal orientation profiles among college students in the United States and found a diffuse, approach-oriented, success-oriented, learning oriented and high performance approach profile. For the six profile solutions found, the four profile solution of the (Tuominen-Soini et al., 2011, 2012) was complemented with a disengaged goal orientation profile and a success-oriented goal orientation profile (Tuominen-Soini et al., 2008). Results from aforementioned studies based on student samples provide a feasible ground for the existence of goal orientation profiles among teachers. However, because the number and type of goal orientation profiles differ per sample no conclusion can be drawn regarding the goal orientation profiles that exist in general. Moreover, all previous studies were performed on samples of students or children, with a wide variety in age ( 8 to 19 years old) and educational level (primary school to college students). Because goal orientations change with age (de Lange, Van Yperen, Van der Heijden, \& Bal, 2010) and the educational context has a strong emphasis on learning while the work context has a predominant focus on performance, goal orientation profiles need to be explored among working professionals to fill this gap in the literature. Because our study is the first to estimate goal orientation profiles in the work domain it is largely explorative and we cannot formulate hypotheses about the exact number and types of profiles that we expect. However, based on studies of students' goal orientation profiles, three up to six goal orientation profiles can be expected. Because of the variety in types of goal orientation profiles that were found in previous studies, we do not have specific expectations for the types of goal orientation profiles in the work domain. 


\section{Goal Orientation and Background Characteristics}

In this study multiple background characteristics were included to explain goal orientation profiles. First, based on the socioemotional selectivity theory (Carstensen, 2006) it can be argued that older workers perceive their time as more limited, leading to less future-focused goals. Therefore, we expect that the level of learning goals will be lower for older teachers compared to younger teachers and that older workers will have a lower motivation to participate in opportunities for learning. Hence, we decided to include age as a background characteristic in our study to explain why individuals are assigned to a specific goal orientation profile.

Second, teachers in vocational education and training have various backgrounds (teaching or work practice) and work together in multidisciplinary teams to provide students with competence-based education (Biemans et al., 2009). Many teachers previously worked in a practical-oriented occupation (i.e. hair dresser or nurse) and were retrained to be a teacher and to strengthen the link between learning and the future workplace of students. This lateral entry in the educational sector can be an explanatory factor when assigning teachers to goal orientation profiles, because teachers that start teaching later in their career might be more insecure and therefore more cautious in taking on tasks that could show their incompetence (Kunter, Frenzel, Nagy, Baumert, \& Pekrun, 2011). This might result in more frequent assignment of these teachers to profiles with high levels of performance avoidance. Another possibility is that to hide their insecurity about their teaching quality, teachers with a previous career in practice are more eager to show their results to others, which will result in an assignment to high performance approach-oriented profiles. Therefore this variable, a previous career outside education, was included as explanatory background characteristic.

The last background characteristic included in this study was gender. We do not expect differences between goal orientation profiles and gender, because previous studies which related single goal orientations to gender did not find significant differences between men and women regarding their goal orientations (Button, Mathieu, \& Zajac, 1996; Hirst, Van Knippenberg, \& Zhou, 2009; Van Yperen, 2006).

\section{Professional Development and Goal Orientation Profiles}

Teachers professional learning activities may take place in formal and informal contexts (Richter, Kunter, Klusmann, Lüdtke, \& Baumert, 2011). Learning activities in formal contexts refer to the participation in planned and structured learning opportunities such as training and education. Learning activities in informal settings are initiated by teachers themselves, are often unplanned and embedded within the school or nearschool environment (Richter et al., 2011; Tynjälä, 2008). This study will specifically focus on two types of teachers' learning activities namely information acquisition and asking for feedback. Teachers can acquire information in both formal settings (e.g. by participation in courses), and informal settings (e.g. by reading about their subject in course manuals, books or on the internet) (Van Offenbeek, 2001). Asking for feedback refers to teachers' initiative to acquire feedback, help or advice from direct colleagues, outsiders or family and friends (Wong, 2004). Both activities refer to self-initiated learning behavior that contribute to improved knowledge and skills (Lohman, 2006). 
We expect that these self-initiated professional learning activities will be related to teachers' goal orientation profile.

Teachers with a high learning goal orientation are likely to be more active in information acquisition as this increases the possibility to improve their knowledge, skills, and abilities (Janssen \& Prins, 2007; Tuckey, Brewer, \& Williamson, 2002; Weiss, Lurie, \& MacInnis, 2008). In contrast, teachers with performance approach goals may acquire information only when they expect this to have a direct impact on their performance or the meeting of expectations (Weiss et al., 2008), whereas teachers who score high on performance avoidance will only acquire information to prevent looking incompetent to others. What we do not know, however, is how information acquisition is affected by a combination of these goal orientations.

Teachers with a strong learning goal orientation perceive feedback as an opportunity to learn and improve (Janssen \& Prins, 2007) and see negative feedback as diagnostic information instead of performance evaluation (Morrison \& Bies, 1991; VandeWalle, 2004). Teachers with a strong performance approach goal orientation view performance feedback as a possibility to justify their competence; on the other hand, positive feedback might give them an ego boost (Tuckey et al., 2002) and a possible negative evaluation of their performance will be avoided to prevent loss of image (Kluger \& Nir, 2010; Morrison \& Bies, 1991). Therefore, we expect that teachers with a profile including a high learning goal orientation participate more frequently in feedback seeking behavior than teachers with a profile with a high score on performanceapproach or avoidance goal orientation.

Although we did not formulate specific hypotheses regarding different goal orientation profiles and their relations to professional development activities, we do have some more generic expectations. First, we expect to find differences in participation in professional development for the different goal orientation profiles. Second, we predict that participation in professional development activities will be higher for teachers assigned to a profile with a moderate-high learning goal orientation score, and lower for teachers with a moderate-high performance avoidance score within a profile. Third, teachers with a combination of moderate-high learning goals and moderate/high performance approach goals are expected to participate more in professional development activities compared to teachers with only moderate/high performance approach goals. This is because teachers with dominant performance approach goals might be more focused on meeting the norms for professional development (i.e. number of hours spent or number of training sessions taken) to avoid negative evaluations and outperform their colleagues. Fourth, when besides a high performance approach goal orientation, a moderate to high learning goal orientation is present, teachers might have more concern for the needs of the others within the school. This is because the performance approach goal orientation makes teachers aware of the others and their expectations and judgements. Therefore, when teachers have a combined profile including moderate to high levels of performance approach goals and moderate to high level of learning goals, the intrinsic motivation to learn and willingness to seek for challenging opportunities can counter the possible negative impact of performance approach goals and stimulate teachers to use knowledge of others. The active acquisition of information and asking for feedback might, therefore, be stimulated when teachers have a combined performance-approach and learning goal orientation profile. 


\section{Method}

\section{Design \& Procedure}

In 2014, we distributed an online questionnaire among 1650 teachers in vocational education and training (VET) in the Netherlands as part of a large national study on team learning in teacher teams in VET. Using telephone and invitation e-mails team leaders and educational managers were invited to participate in this study. All participating teachers received an invitation for the online questionnaire via e-mail. Teams that participated received a report including an overview of their average team scores as a reward for their participation.

\section{Participants}

A total number of 1147 teachers of 104 teacher teams from 23 vocational education and training institutions participated (response rate $=69.51 \%$ ). From the 503 non-respondents, 30 teachers started the questionnaire but did not answer any question, and 473 respondents did not click on the link in the respondents' e-mail at all. From all respondents, 984 were full respondents to every scale (full response rate $=59.63 \%$ ) and 163 were partial respondents who stopped after completion of the questions about demographics (age, gender, years of experience and work experience) (partial response rate $=9.88 \%$ ). For these 163 respondents, all items measuring goal orientation, information acquisition and asking for feedback were missing. After deleting cases with missing values on the main variables in this study, 984 teachers were retained. The average age of the teachers in our sample was 47.42 (range between 21 and 68 years). In our sample 507 (51.5\%) women and 466 men participated (comparable to $48 \%$ females in the overall population; Central Bureau for Statistics, 2016). At least $80 \%$ of the teachers had a higher vocational education or university background (comparable to $76.7 \%$ in the overall population; Central Bureau for Statistics, 2016).

\section{Measures}

Goal Orientation All three scales from the work domain goal orientation instrument developed by VandeWalle (1997) were used. Learning goal orientation was measured with five items (e.g., "I am willing to select a challenging work assignment that I can learn a lot from"), Cronbach's $\alpha=.82$. Performance approach goal orientation was measured with four items (e.g., "I enjoy it when others at work are aware of how well I am doing"), Cronbach's $\alpha=.81$. The performance avoidance goal orientation was also measured with four items (e.g., "I'm concerned about taking on a task at work if my performance would reveal that I had low ability."), Cronbach's $\alpha=.81$. A 5-point Likert scale was used $(1=$ totally disagree and $5=$ totally agree $)$. The confirmatory factor analysis suggested that the three factor structure fit the data appropriately, $\chi^{2}(62)=300.996, p<.001, \mathrm{RMSEA}=.059, \mathrm{TLI}=.937, \mathrm{CFI}=.950, \mathrm{SRMR}=.054$ and significantly better in comparison to a one-factor model $\chi^{2}(65)=2348.047$ $p<.001, \mathrm{RMSEA}=.200, \mathrm{CFI}=.521, \mathrm{TLI}=.425, \mathrm{SRMR}=.172$, and a two-factor model (learning goal orientation versus performance goals); $\chi^{2}(64)=642.753 p<.001$, RMSEA $=.166, \mathrm{TLI}=.606, \mathrm{CFI}=.677, \mathrm{SRMR}=.181$. 
Information Acquisition Information acquisition was measured with three items from the team learning scale developed by Van Offenbeek (2001) and two items that measured participation in training (see Appendix). An example item is: "I participate in meetings outside the school (e.g., courses, conferences, or workshops)". A 5-point Likert scale $(1=$ never and $5=$ always $)$ was used. Cronbach's alpha for this scale was .63. The confirmatory factor analysis suggested acceptable data fit, $\chi^{2}(5)=45.747$, $p<.001, \mathrm{RMSEA}=.091, \mathrm{TLI}=.866, \mathrm{CFI}=.933, \mathrm{SRMR}=.034$.

Feedback Asking Behavior To measure feedback asking behavior, the four item distal learning scale of Wong (2004) was used. The referent was shifted from "we" to "I" to be able to measure this construct for individual analysis (see Appendix). A 5-point Likert scale was used $(1=$ never and $5=$ always $)$. An example item is: "I obtain help and advice from people external to the team". Cronbach's alpha for this scale was .78. The confirmatory factor analysis suggested good data fit, $\chi^{2}(2)=20.149, p<.001$, RMSEA $=.096, \mathrm{TLI}=.95, \mathrm{CFI}=.99, \mathrm{SRMR}=.022$.

\section{Statistical Analyses}

The statistical analyses in this study were carried out in multiple steps. First, preliminary analyses were conducted to evaluate if it was necessary to perform multilevel analyses because teachers were nested in teams. Therefore, we calculated the ICC(1) and ICC(2) for all variables. The ICC(1)-scores, indicating the proportion of variance between the teams, ranged between -.007 (learning goal orientation) and .022 (asking for feedback and information acquisition). Furthermore, the ICC(2)-scores, corresponding with the reliability of the group mean, varied between -.106 (learning goal orientation) and .234 (information acquisition). These results indicate that controlling for the nested data-structure was not needed and individual level variables could be used in the analyses (LeBreton \& Senter, 2008). Although negative intra class correlations are quite rare, these may occur when the within-group variance is smaller compared to the between-group variance (Woehr, Loignon, Schmidt, Loughry, \& Ohland, 2015; Bliese, 2000). Second, a latent profile analysis was performed to identify goal orientation profiles of teachers in the sample. Based on the number of profiles found in previous research, $k=1$ to $k=10$ profiles were evaluated using Mplus 7.3 (Muthén \& Muthén, 1998-2015) in order to identify distinct profiles. Multiple criteria were used to evaluate the model fit. The statistical analyses in this study were carried out in multiple steps. First, a latent profile analysis was performed to identify goal orientation profiles of teachers in the sample. Based on the number of profiles found in previous research, $\mathrm{k}=1$ to $\mathrm{k}=10$ profiles were evaluated using Mplus 7.3 (Muthén \& Muthén, 1998-2015) in order to identify distinct profiles. In line with Nylund, Asparouhov, and Muthén (2007) multiple criteria were used to evaluate the model fit. First, the Bootstrap Likelihood Ratio Test (BLRT) (Nylund et al., 2007) was used to test whether a k-profile model had a significantly better absolute fit compared to a k-1 model. The null hypothesis for the BLRT is that no increase in model fit is obtained by adding an extra profile. When BLRT is not significant the number of profiles should not be increased any further. Second, the Bayesian Information Criterion (BIC) was used to compare the relative fit of multiple models to the data, while penalizing each model for 
its complexity (i.e. the number of parameters) and the sample size. That is, a lower BIC indicates a better fit/complexity trade-off. In a last step, the entropy and smallest profile size were used to verify the model fit. The value of the entropy shows the ability of the profile solution to assign individuals to the correct profile. A value above .70 is used as a rule-of-thumb for appropriate model fit. To have an acceptable minimum number of individuals in each profile we required the smallest profile to include at least $5 \%$ of the individuals of the sample (Nylund et al., 2007). A good statistical and theoretical fit of the final profile solution was of overriding importance in selecting the number or profiles.

Having identified the appropriate number of goal orientation profiles, using the 3Step approach in Mplus (Asparouhov \& Muthén, 2014) mean score differences tests were used to compare the latent profiles on teacher characteristics (gender, age, work experience, work experience outside education) and the professional development activities information acquisition and asking feedback. This approach is comparable to the often applied multinomial logistic regression analysis approach to compare mean scores. In the 3-step approach first, the latent profile model was estimated. Second, the most likely latent profile probability was computed for each teacher in the sample. Based on these probabilities a classification of uncertainty was computed taking into account the possibility of misclassification. In the third step, the distal outcomes (information acquisition and asking for feedback) were included and compared based on the mean scores. In this step, the most likely latent class membership (step 1) was used as an indicator while the uncertainty rate (step 2) was used as a covariate to control for classification errors (Asparouhov \& Muthén, 2014).

\section{Results}

\section{Descriptive Statistics}

Table 1 presents the means, standard deviations, and correlations between the three goal orientations, professional development activities and teacher characteristics. Based on the correlations presented in Table 1 one can derive that the three goal orientations correlate weakly to moderately with each other.

Information acquisition was positively correlated with a learning goal orientation, $r=.38, p<.001$. In line with our expectations, learning goal orientation $(r=.28$, $p<.001)$ and performance approach goal orientation $(r=.14, p<.001)$ were positively related to asking feedback and performance avoidance was negatively associated with asking feedback $(r=-.14, p<.001)$. Work experience outside education showed a positive correlation with the learning goal orientation $(r=.20, p<.001)$ and a negative correlation with the performance avoidance goal orientation $(r=-.11, p<.001)$.

\section{Identification of Teacher's Goal Orientation Profiles}

Prior to the latent profile analysis, a confirmatory factor analysis was performed to verify whether the trichothomous goal orientation structure was well identified. The factor scores were saved and used as indicators for the latent profiles. A latent profile analysis was conducted to identify the number of goal orientation profiles 
Table 1 Univariate descriptive statistics and correlations

\begin{tabular}{|c|c|c|c|c|c|c|c|c|c|c|}
\hline Measure & 1 & 2 & 3 & 4 & 5 & 6 & 7 & 8 & 9 & 10 \\
\hline 1. Learning GO & - & & & & & & & & & \\
\hline 2. P-Approach GO & $.21^{* *}$ & - & & & & & & & & \\
\hline 3. P-Avoidance GO & $-.36^{* *}$ & $.19^{* * *}$ & - & & & & & & & \\
\hline 4. Asking Feedback & $.28^{* *}$ & $.14^{* *}$ & $-.14^{* *}$ & - & & & & & & \\
\hline 5. Information Acquisition & $.38^{* *}$ & $.09^{* *}$ & $.09^{* *}$ & $.48^{* *}$ & - & & & & & \\
\hline 6. Age & $-.15^{* *}$ & $-.14^{* *}$ & .06 & $-.13^{* *}$ & -.03 & - & & & & \\
\hline 7. Gender ( 1 = Male $)$ & .05 & $.07^{* *}$ & .04 & .03 & .06 & $.13^{* *}$ & - & & & \\
\hline $\begin{array}{l}\text { 8. Work Experience Outside } \\
\text { Education }^{\text {a }}\end{array}$ & $.20^{* *}$ & .06 & $-.11^{* *}$ & $.09^{* *}$ & $09^{* *}$ & $.09^{* *}$ & $.10^{* *}$ & - & & \\
\hline 9. Working Hours & .05 & .05 & .02 & .03 & .06 & $.13^{* *}$ & $.29^{* *}$ & $-.09^{*}$ & - & \\
\hline 10. Years in Education & $-.19^{* *}$ & $-.11^{* *}$ & $.11^{* *}$ & $-.11^{* *}$ & -.01 & $.68^{* * *}$ & $.09^{* *}$ & $-.30^{* *}$ & $.14^{* *}$ & - \\
\hline$M$ & 0 & 0 & 0 & 2.52 & 3.31 & 47.42 & $48 \%$ & .73 & 36.4 & 14.76 \\
\hline$S D$ & 1 & 1 & 1 & .64 & .63 & 11.15 & & .445 & .18 & 10.73 \\
\hline
\end{tabular}

$N=882{ }^{a}$ Did you had a previous career outside education? $(1=\mathrm{Yes}, 0=\mathrm{No}) . * p<.05, * * p<.01 . \mathrm{GO}=\mathrm{Goal}$ Orientation

of the respondents. Table 2 presents the profile solutions for $k=1$ to $k=10$ latent profiles. As can be seen in this table, the BIC declined when adding extra profiles and the BLRT stayed non-significant indicating that a higher number of profiles could be preferred above a lower number of profiles. The entropy was not high (> .80) but from the 5-profile and 6-profile model onwards, it exceeded the .70 minimum value. Based on the smallest number of teachers assigned to the profiles the 5-profiles model was used for interpretation and further analyses. To interpret and label the different goal orientation profiles the guidelines of Luo et al. (2011), using the standardized mean score were adopted. A standardized mean score below -1 indicated a low score on a specific goal orientation, a standardized mean score below 1 was interpreted as a high score on specific goal orientation, and a score between -1 and 1 was labelled as 'moderate'.

Figure 1 illustrates the standardized mean scores on the goal orientation profiles. Half of the teachers $(50.1 \%)$ were assigned to the largest profile (the diffuse profile) and demonstrated scores close to the means of all scales. These teachers did not show a preference for one of the three goal orientations. The other half of the teachers were almost equally divided among the four other profiles. Moderatelearning $(12.3 \%)$ teachers scored average on learning goal orientation but low on performance approach and performance avoidance goals. High-avoidance teachers $(10.9 \%)$ scored high on the performance avoidance orientation and low on the learning goal orientation. Performance-oriented teachers $(15.9 \%)$ scored high on performance avoidance and relatively high on performance approach orientation and around average for the learning goal orientation. The last category includes success-oriented teachers $(10.7 \%)$ with a high level of learning goal orientation and a moderate high performance approach goal orientation. 
Table 2 Description of model fit statistics for $k=1$ to $k=10$ goal orientation profiles

\begin{tabular}{llllll}
\hline & & & \multicolumn{3}{c}{ Smallest profile size } \\
$k$ & $B L R T$ & $B I C$ & Entropy & $N$ & $\%$ \\
\hline 1 & - & 8416 & 1.00 & 984 & 100 \\
2 & $<.001$ & 8307 & .506 & 426 & 43.2 \\
3 & $<.001$ & 8235 & .562 & 168 & 17.1 \\
4 & $<.001$ & 8192 & .655 & 78 & 7.9 \\
5 & $<.001$ & 8159 & .709 & 92 & 11.9 \\
6 & $<.001$ & 8149 & .727 & 22 & 2.2 \\
7 & $<.001$ & 8086 & .777 & 35 & 3.5 \\
8 & $<.001$ & 8090 & .786 & 6 & 0.6 \\
9 & .1538 & 8106 & .793 & 5 & 0.5 \\
10 & .1053 & 8120 & .804 & 7 & 0.7 \\
\hline
\end{tabular}

$B L R T=$ Bootstrap Likelihood Ratio Test. $B I C=$ Bayesian Information Criterion

\section{Goal Orientation Profiles and Background Characteristics}

To gain more insight into the individual characteristics that were related to each profile, we calculated a mean score on demographic (gender, age), and career characteristics (work experience outside education, work experience in education and number of working hours per week; see Table 3). Although there was a roughly equal number of men and women in the overall sample, respondents in the success-oriented and performance-oriented profile were significantly more often male whereas respondents with a high avoidance profile were more often female. The average age differences between the profiles were small, although the high avoidance profile was the oldest. Work-related background characteristics such as work experience outside education,

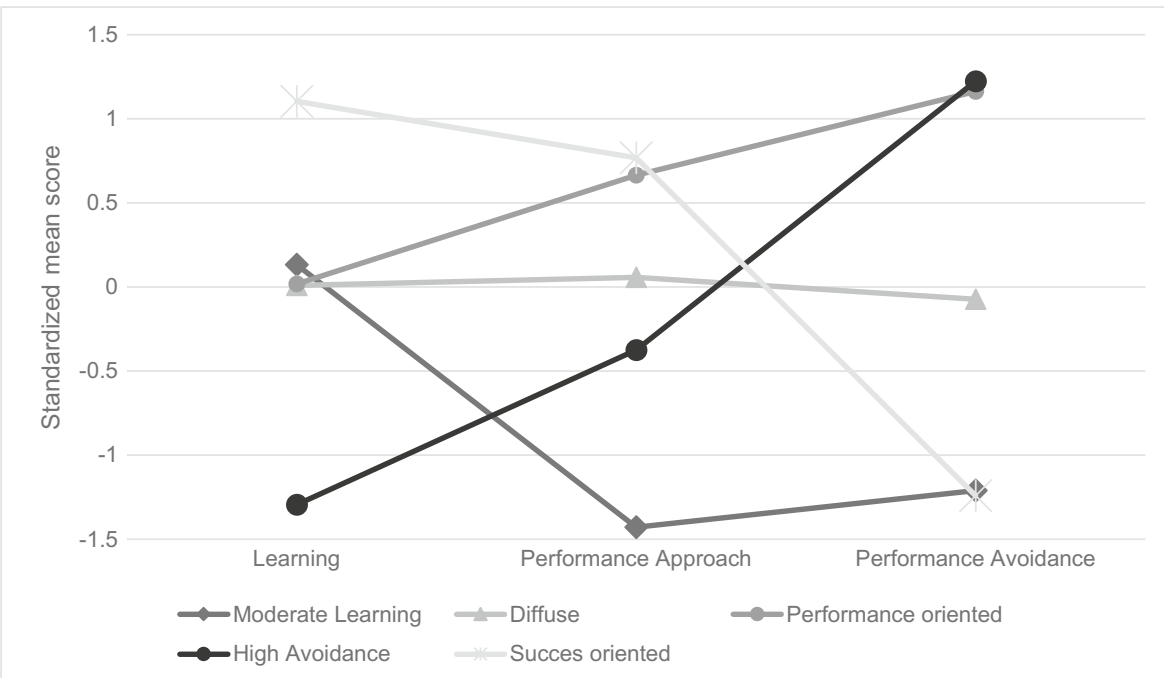

Fig. 1 Standardized means for the goal orientations in the five goal orientation profiles 
years of work experience in education, and number of working hours showed that success-oriented and performance-oriented teachers had more often work experience outside education compared to teachers with a high-avoidance profile. Teachers with a high avoidance profile had the highest work experience within education and had least frequently worked outside education. The number of working hours per week did not differ significantly across the goal orientation profiles.

\section{Goal Orientation Profiles and Professional Development}

To examine mean score differences between the profiles on information acquisition and asking for feedback, the 3-step procedure for distal outcomes was used (Asparouhov \& Muthén, 2014). The results in Table 4 show three patterns of comparison that are similar for both information acquisition and asking feedback. First, the success-oriented profile (high learning combined with high performance approach goals) exceeded all other profiles in terms of the mean scores on information acquisition and asking for feedback. When the other profiles were compared to the success-oriented profile, all other profiles score significantly lower. Second, in contrast, the high avoidance profile has the lowest scores on information acquisition and asking for feedback compared to the four other profiles. And third, the moderate-learning, diffuse and performanceoriented profile do not show significant mean differences between the profiles, on information acquisition and asking feedback.

\section{Discussion}

The current study investigated the existence of goal orientation profiles among teachers. Five different goal orientation profiles were found within a sample of 984 teachers from vocational education and training institutions. Most teachers in our study were assigned to the diffuse profile, with a moderate representation of all goal orientations. This finding is similar to previous studies on students' samples that all identified a diffuse goal orientation profile. The four other profiles that we found were also in line with previous studies. The performance oriented profile (scoring high on

Table 3 Mean score comparison on background characteristics

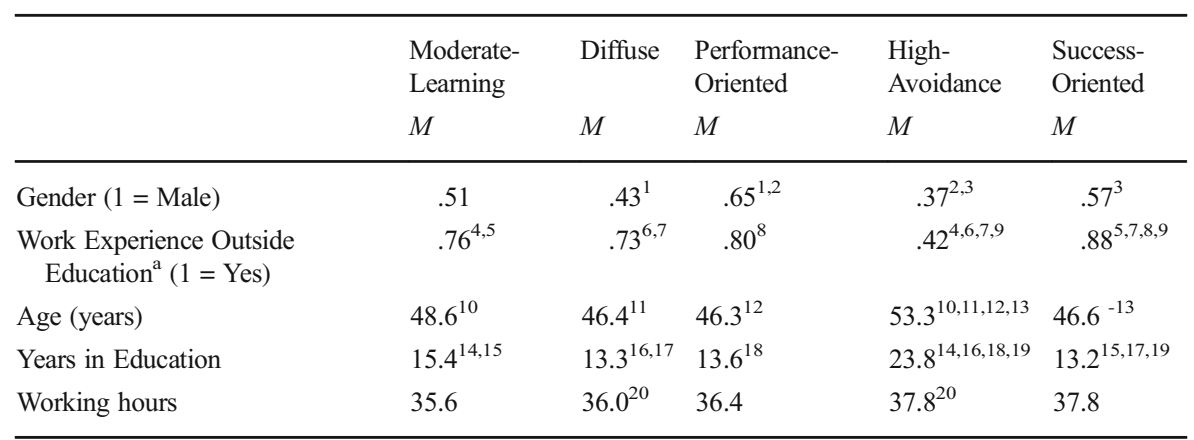

Equal subscripts indicate significant mean differences between the profiles. ${ }^{a}$ Did you have a previous career outside education? 
Table 4 Mean scores on asking feedback and information acquisition for all goal orientation profiles

\begin{tabular}{|c|c|c|c|c|c|}
\hline & $\begin{array}{l}\text { Moderate } \\
\text { Learning }\end{array}$ & Diffuse & $\begin{array}{l}\text { Performance } \\
\text { oriented }\end{array}$ & $\begin{array}{l}\text { High } \\
\text { Avoidance }\end{array}$ & $\begin{array}{l}\text { Success- } \\
\text { oriented }\end{array}$ \\
\hline & $M$ & $M$ & $M$ & $M$ & $M$ \\
\hline $\begin{array}{l}\text { Information } \\
\text { Acquisition }\end{array}$ & $3.43^{1,2}$ & $3.26^{3,4}$ & $3.36^{5,6}$ & $2.89^{1,3,6,7}$ & $3.74^{2,4,5,7}$ \\
\hline Asking Feedback & $2.48^{1,2}$ & $2.51^{3,4}$ & $2.53^{5,6}$ & $2.16^{1,3,6,7}$ & $2.96^{-2,4,5,7}$ \\
\hline
\end{tabular}

Equal symbols indicate significant mean differences between the profiles

both performance approach and performance avoidance goals) was reported by Luo et al. (2011) and by Tuominen-Soini et al. (2008, 2001, 2012).The success-oriented profile (scoring high on both learning and performance approach goals) was identified in the study of Luo et al. (2011) and Pastor et al. (2007). The moderate learning profile was also found by Luo et al. (2011) and the high avoidance profile was identified in the studies of Tuominen-Soini et al. (2008, 2011, 2012). So although goal orientations change with age (de Lange et al., 2010) and the educational context has a strong emphasis on learning whereas the work context has a predominant focus on performance, goal orientation profiles of working professionals appear to be quite similar to those of students. By demonstrating the existence of goal orientation profiles for teachers, our study contributes to the research on teachers' goal orientations (Butler, 2007; Skaalvik \& Skaalvik, 2013) which until now has primarily focused on single goal orientations instead of combinations of goal orientations (Pastor et al., 2007). Studying goal orientation profiles improves the insight into the buffer and/or boosting function of having multiple goal orientations at the same time (Barron \& Harackiewicz, 2001).

Relating the goal orientation profiles to professional development activities showed that a combination of high learning goals, high performance approach goals, and low performance avoidance goals (success-oriented profile) resulted in the highest mean score on both professional development activities. This illustrates that not only a high learning goal orientation but the specific combination with high performance approach goals is associated with more participation in professional development activities. Teachers with a success-oriented profile are focused on the understanding of tasks and like to enter challenging environments where they can learn and simultaneously enjoy opportunities to show successful performances to others. This is in line with previous research indicating that individuals with a high learning or performance goal orientation have a higher ability to cope with complex situations because they work with persistence towards successful task completion (Elliot \& McGregor, 2001; Kaplan, Middleton, Urdan, \& Midgley, 2002).

Unfortunately, we cannot draw conclusions about whether a learning goal orientation can function as a buffer for a high performance avoidance orientation, and thereby result in less detrimental outcomes in terms of participation in learning activities, as suggested by Barron and Harackiewicz (2001). Although we identified three profiles with a moderate learning goal orientation (performance oriented, moderate learning, and performance avoidance) in combination with various levels of performance approach and performance avoidance orientation, the levels of learning goal orientation in 
these profiles are close to each other, leading to difficulties in identifying the impact of performance-approach and performance-avoidance goals in coexistence with learning goals.

Although the success-oriented profile was the most favorable profile in terms of professional development activities, only a minority of teachers were assigned to this profile. The majority of teachers turned out to have a diffuse goal orientation profile, scoring averagely on the three goal orientations. For teachers in this diffuse profile, the positive impact of the combination of moderate levels of performance approach and learning goals might be limited because the average levels of performance avoidance goals will have a restraining impact on participation in learning activities (Jansen in de Wal et al., 2016). This lowering impact of performance avoidance goals can be explained by the fear to fail when colleagues are nearby and in the position to judge a teacher's performance. When there is a chance that other teachers can express negative judgements, for example via feedback, those teachers might evade colleagues to prevent themselves from negative judgements on performance.

Our results show that teachers with a diffuse profile participate less in professional development activities compared to teachers in profiles with higher levels of learning and performance approach goals. Although these teachers do feel the need to keep up with the new developments and literature in their field and are willing to ask feedback they might be distant to participation when there is a chance of task failure or negative judgement of colleagues. Task withdrawal in the form of low participation in information acquisition activities and not asking feedback is an approach to prevent negative judgements, instead of learning from negative feedback (Button et al., 1996).

Post-hoc comparisons on background characteristics showed interesting differences among the goal orientation profiles. These comparisons pointed out that on average, older teachers were more often assigned to the performance avoidance profile. This is in line with the socioemotional selectivity theory (Carstensen, 2006). This theory poses that older workers put less energy in the development and enrichment of knowledge because they focus more on short-term goals (social interaction, good work atmosphere, and current work performance). The preference of older workers to focus on not performing worse than before and the shift over time from a learning goal orientation towards performance avoidance or performance approach oriented goal orientations have been confirmed in previous research (de Lange et al., 2010). When workers age, the self-perception of one's performance might become negative due to psychological constraints (being less able to process information or to deal with high work pressure) and physiological constraints (less energy, limited mobility). Moreover, the fear of performing worse than before in new achievement situations is strengthened (Elliot \& Dweck, 2005).

Other relevant background characteristics that resulted in significant mean differences between the profiles are work experience (years) and work experience outside education. Specifically, we found that teachers with experience outside education were more often assigned to the performance-oriented or success-oriented profile. These two profiles have a high performance approach goal in common, indicating that teachers with previous work experience outside education have a focus on showing their competence in task performance, and are eager to seek for feedback from colleagues. This finding may be explained by the individual orientation of the teaching profession. In general, teachers are strongly focused on individual task performance and are not 
used to collaboration within a team (Helstad \& Lund, 2012; Vangrieken, Dochy, \& Raes, 2016). However, teachers with much work experience outside education might be more used to collaboration and working towards common team goals and might therefore also be more used to receiving and asking feedback.

\section{Limitations and Future Research}

A first limitation of this study is its cross-sectional nature, implying that we cannot make claims regarding causality and that we do not know how stable goal orientation profiles are over time and across different situations. Within the literature, a long standing debate exists about whether goals orientation should be seen as states, traits or quasi-traits. A majority of studies treat goal orientation as a quasi-trait that might slightly change depending on the situation (DeShon \& Gillespie, 2005). Future studies with a longitudinal design would provide the opportunity to verify the stability of goal orientation profiles and to identify predictors of changes across profiles. For instance, it could be examined to what extent coaching leadership may stimulate teachers to move from a more diffuse or performance-avoidance profile towards a learning dominated goal orientation profile.

This study was the first to investigate goal orientation profiles of teachers. Although the number of respondents within this study provided enough power to estimate latent profiles (Gudicha, Tekle, \& Vermunt, 2016) our results cannot be generalized to the complete population of teachers, which might have different background characteristics compared to the VET-college teachers used in this sample. Replication of our study in other educational sectors (primary education, secondary education, higher education) is needed to validate the number and content of goal orientation profiles. Moreover, future research should point out to what extent goal orientation profiles predict teacher cognitions and behaviors such as self-efficacy (Runhaar et al., 2010; Schiefele \& Schaffner, 2015; Throndsen \& Turmo, 2013; Butler, 2007; Cho \& Shim, 2013; Deemer, 2004; Inbar-Furst \& Gumpel, 2015; Kilday, Lenser, \& Miller, 2016; Künsting, Neuber, \& Lipowsky, 2016; Kucsera, Roberts, Walls, Walker, \& Svinicki, 2011; Hoffmann, Huff, Patterson, \& Nietfeld, 2009); proactive behavior (Zhang et al., 2016); instructional practices (Nitsche et al., 2013; Retelsdorf et al., 2010), and engagement (Han et al., 2016; Kunsting et al., 2016; Parker et al., 2012; Skaalvik \& Skaalvik, 2013).

In this study, we included information acquisition and asking for feedback only as indicators of teachers' professional development. Future research on teachers' goal orientation profiles and professional development might therefore include other professional development activities such as collaborative learning (Levine \& Marcus, 2010), team learning (Ohlsson, 2013; Vangrieken et al., 2016) or critically reflective work behavior (Van Woerkom \& Croon, 2008).

More research focusing on the individual needs of teachers based on their career phase, personal characteristics and goal orientation profiles could contribute to the development of tailor-made professional development practices. Also, future research including context variables such as a school climate, leadership styles of managers and job demands such as work pressure could provide more concrete directions for interventions that may stimulate teachers to change towards learning-oriented or success-oriented profiles. A last limitation of our study is that we used Vandewalle's 
(1997) instrument which only includes learning, performance approach and performance avoidance goal orientations. We decided to use Vandewalle's instrument because it is validated in a wide range of sectors (education, sports, health care, finance), thereby strengthening the generalizability of our results. Nevertheless, future research might also include mastery avoidance goals, which refer to the prevention of the loss of knowledge (Baranik, Stanley, Bynum, \& Lance, 2010). Teachers who score high on this construct strive for maintaining their levels of performance, avoiding to perform worse compared to previous performance (Van Yperen \& Orehek, 2013). Including mastery avoidance goals might give a more refined perspective on the high avoidance goal orientation profile. Including work avoidance goals (referring to a preference for tasks that do not involve significant effort) might also contribute to more detailed knowledge about the high-avoidance goal orientation profile.

\section{Practical Implications}

The results of the current study suggest that schools with a majority of older women, who are more likely to adopt a performance-avoidance goal orientation profile, could experiment with approaches to enhance their learning goal orientation and thereby stimulate their participation in professional development activities. Teachers with an avoidance-oriented profile are known to be more anxious to show failure to their environment. This fear prevents these teachers to participate in professional learning tasks. Possibly, a safe environment, supporting different perspectives and opinions will support them in taking on new and challenging tasks even if there is a chance of failing (Edmondson, 1999). A team leader demonstrating transformational leadership is likely to contribute to this safe environment by stimulating teachers to take risks and by emphasizing the importance of learning instead of only performance (Runhaar et al., 2010).

\section{Conclusion}

This study was the first to study the coexistence of different goal orientations in the context of work. Five goal orientation profiles were identified that are distinctive in content, with half of the teachers being assigned to a diffuse profile with an equal orientation on learning goals, performance approach goals, and performance avoidance goals. Teachers with a success-oriented profile (a combination of high values of learning and performance approach goals and low scores on performance avoidance goals) demonstrated the highest level of participation in professional development activities. Our results showed that high learning goal orientation profiles are associated with the most participation in learning activities and that high avoidance profiles are associated with the least participation in professional development activities. The individual characteristics of age, work experience and gender showed to be distinctive factors between the goal orientation profiles. Specifically, the high avoidance profile (low learning and performance approach goals and high performance avoidance goals) included more females and more older workers, and the success-oriented profile contains more teachers with previous work experience outside education. 


\title{
Appendix. Questionnaires
}

\author{
Information acquisition (based on Van Offenbeek, 2001)
}

1. I collect professional information from books, journals, television, or internet

2. I try out new work methods or procedures

3. I participate in meetings outside the school (e.g., courses, conferences, or workshops)

4. I ask my team members for help or advice on my work

5. I participate in meetings inside the school (e.g., workshops)

Feedback asking behavior (based on Wong, 2004)

1. I review the team's work with people external to the team

2. I obtain help or advice from people external to the team

3. I seek ideas and/or expertise from people external to the team

4. I seek feedback about the team's work from people external to the team

Open Access This article is distributed under the terms of the Creative Commons Attribution 4.0 International License (http://creativecommons.org/licenses/by/4.0/), which permits unrestricted use, distribution, and reproduction in any medium, provided you give appropriate credit to the original author(s) and the source, provide a link to the Creative Commons license, and indicate if changes were made.

\section{References}

Ames, C., \& Ames, P. (1984). System of student and teacher motivation towards a qualitative definition. Journal of Educational Psychology, 76(4), 535-556.

Asparouhov, T., \& Muthén, B. (2014). Auxiliary variables in mixture modeling: Three-step approaches using Mplus. Structural Equation Modeling: A Multidisciplinary Journal, 21(3), 329-341.

Baranik, L. E., Stanley, L. J., Bynum, B. H., \& Lance, C. E. (2010). Examining the construct validity of mastery-avoidance achievement goals: A meta-analysis. Human Performance, 23(3), 265-282.

Barron, K. E., \& Harackiewicz, J. M. (2001). Achievement goals and optimal motivation: Testing multiple goal models. Journal of Personality and Social Psychology, 80(5), 706-722.

Biemans, H., Wesselink, R., Gulikers, J., Schaafsma, S., Verstegen, J., \& Mulder, M. (2009). Towards competence based VET: Dealing with the pitfalls. Journal of Vocational Education \& Training, 61(3), 267-286.

Bliese, P. D. (2000). Within-group agreement, non-independence, and reliability: Implications for data aggregation and analysis. In K. J. Klein \& S. W. J. Kozlowski (Eds.), Multilevel theory, research, and methods in organizations: Foundations, extensions, and new directions. San Francisco: Jossey-bass.

Butler, R. (2007). Teachers' achievement goal orientations and associations with teachers' help seeking: Examination of a novel approach to teacher motivation. Journal of Educational Psychology, 99(2), 241-252.

Butler, R., \& Shibaz, L. (2008). Achievement goals for teaching as predictors of students' perceptions of instructional practices and students' help seeking and cheating. Learning and Instruction, 18(5), 453-467.

Button, S. B., Mathieu, J. E., \& Zajac, D. M. (1996). Goal orientation in organizational research: A conceptual and empirical foundation. Organizational Behavior and Human Decision Processes, 67(1), 26-48.

Carstensen, L. L. (2006). The influence of a sense of time on human development. Science, 312(5782), 1913-1915.

Central Bureau for Statistics. (2016). Statistics Netherlands: Dutch labor force. Database. http://statline.cbs. $\mathrm{nl} /$ Statweb/publication/?DM=SLNL\&PA=8208NED\&D1=0\&D2=a\&D3=0-18\&D4=0\&D5=1\&VW=T. Accessed May 262016.

Cho, Y., \& Shim, S. S. (2013). Predicting teachers' achievement goals for teaching: The role of perceived school goal structure and teachers' sense of efficacy. Teaching and Teacher Education, 32, 12-21.

Chughtai, A. A., \& Buckley, F. (2010). Assessing the effects of organizational identification on in-role job performance and learning behaviour: The mediating role of learning goal orientation. Personnel Review, $39(2), 242-258$. 
de Lange, A. H., Van Yperen, N. W., Van der Heijden, B. I., \& Bal, P. M. (2010). Dominant achievement goals of older workers and their relationship with motivation-related outcomes. Journal of Vocational Behavior, $77(1), 118-125$.

Deemer, S. (2004). Classroom goal orientation in high school classrooms: Revealing links between teacher beliefs and classroom environments. Educational Research, 46(1), 73-90.

DeShon, R. P., \& Gillespie, J. Z. (2005). A motivated action theory account of goal orientation. Journal of Applied Psychology, 90(6), 1096-1127.

Dweck, C. S. (1986). Motivational processes affecting learning. American Psychologist, 41(10), 1040-1048.

Dweck, C. S. (1990). Self-theories and goals: Their role in motivation, personality, and development. In R. Dienstbier (Ed.), Nebraska symposium on motivation (Vol. 38, pp. 199-235). Lincoln: University of Nebraksa Press.

Edmondson, A. (1999). Psychological safety and learning behavior in work teams. Administrative Science Quarterly, 44(2), 350-383.

Elliot, A. J., \& Dweck, C. S. (2005). A conceptual history of the achievement goal construct. In A. J. Elliot \& C. Dweck (Eds.), Handbook of competence and motivation (pp. 52-72). New York: The Guilford Press.

Elliot, A. J., \& McGregor, H. A. (2001). A $2 \times 2$ achievement goal framework. Journal of Personality and Social Psychology, 80(3), 501-519.

Eraut, M. (2004). Informal learning in the workplace. Studies in Continuing Education, 26(2), 247-273.

Gudicha, D. W., Tekle, F. B., \& Vermunt, J. K. (2016). Power and sample size computation for Wald tests in latent class models. Journal of Classification, 33(1), 30-51.

Han, J. Y., Yin, H. B., \& Wang, W. L. (2016). The effect of tertiary teachers' goal orientations for teaching on their commitment: The mediating role of teacher engagement. Educational Psychology, 36(3), 526-547.

Helstad, K., \& Lund, A. (2012). Teachers' talk on students' writing: Negotiating students' texts in interdisciplinary teacher teams. Teaching and Teacher Education, 28(4), 599-608.

Hirst, G., Van Knippenberg, D., \& Zhou, J. (2009). A cross-level perspective on employee creativity: Goal orientation, team learning behavior, and individual creativity. Academy of Management Journal, 52(2), 280-293.

Hoffmann, K. F., Huff, J. D., Patterson, A. S., \& Nietfeld, J. L. (2009). Elementary teachers' use and perception of rewards in the classroom. Teaching and Teacher Education, 25(6), 843-849.

Inbar-Furst, H., \& Gumpel, T. P. (2015). Factors affecting female teachers' attitudes toward help-seeking or help-avoidance in coping with behavioral problems. Psychology in the Schools, 52(9), 906-922.

Janssen, O., \& Prins, J. (2007). Goal orientations and the seeking of different types of feedback information. Journal of Occupational and Organizational Psychology, 80(2), 235-249.

Jansen in de Wal, J., Hornstra, L., Prins, F. J., Peetsma, T., \& Van der Veen, I. (2016). The prevalence, development and domain specificity of elementary school students' achievement goal profiles. Educational Psychology, 36(7), 1303-1322.

Kaplan, A., Middleton, M. J., Urdan, T., \& Midgley, C. (2002). Achievement goals and goal structures (goals, goal structures, and patterns of adaptive learning). New York: Routledge.

Kilday, J. E., Lenser, M. L., \& Miller, A. D. (2016). Considering students in teachers' self-efficacy: Examination of a scale for student-oriented teaching. Teaching and Teacher Education, 56, 61-71.

Kluger, A. N., \& Nir, D. (2010). The feedforward interview. Human Resource Management Review, 20(3), $235-246$.

Kolić-Vehovec, S., Rončević, B., \& Bajšanski, I. (2008). Motivational components of self-regulated learning and reading strategy use in university students: The role of goal orientation patterns. Learning and Individual Differences, 18(1), 108-113.

Kucsera, J. V., Roberts, R., Walls, S., Walker, J., \& Svinicki, M. (2011). Goal orientation towards teaching (GOTT) scale. Teachers and Teaching, 17(5), 597-610.

Kunsting, J., Neuber, V., \& Lipowsky, F. (2016). Teacher self-efficacy as a long-term predictor of instructional quality in the classroom. European Journal of Psychology of Education, 31(3), 299-322.

Kunter, M., Frenzel, A., Nagy, G., Baumert, J., \& Pekrun, R. (2011). Teacher enthusiasm: Dimensionality and context specificity. Contemporary Educational Psychology, 36(4), 289-301.

Kwakman, K. (2003). Factors affecting teachers' participation in professional learning activities. Teaching and Teacher Education, 19(2), 149-170.

LeBreton, J. M., \& Senter, J. L. (2008). Answers to 20 questions about interrater reliability and interrater agreement. Organizational Research Methods, 11(4), 815-852.

Lee, O., \& Anderson, C. W. (1993). Task engagement and conceptual change in middle school Science classrooms. American Educational Research Journal, 30(3), 585-610.

Levine, T. H., \& Marcus, A. S. (2010). How the structure and focus of teachers' collaborative activities facilitate and constrain teacher learning. Teaching and Teacher Education, 26(3), 389-398.

Levy, I., Kaplan, A., \& Patrick, H. (2004). Early Adolescents' achievement goals, social status, and attitudes towards cooperation with peers. Social Psychology of Education, 7(2), 127-159. 
Lohman, M. C. (2005). A survey of factors influencing the engagement of two professional groups in informal workplace learning activities. Human Resource Development Quarterly, 16(4), 501-527.

Lohman, M. C. (2006). Factors influencing teachers' engagement in informal learning activities. Journal of Workplace Learning, 18(3), 141-156.

Luo, W., Paris, S. G., Hogan, D., \& Luo, Z. (2011). Do performance goals promote learning? A pattern analysis of Singapore students' achievement goals. Contemporary Educational Psychology, 36(2), 165-176.

Merz, E. L., \& Roesch, S. C. (2011). A latent profile analysis of the five factor model of personality: Modeling trait interactions. Personality and Individual Differences, 51(8), 915-919.

Morrison, E. W., \& Bies, R. J. (1991). Impression Management in the Feedback-Seeking Process: A Literature review and research agenda. Academy of Management Review, 16(3), 522-541.

Muthén, \& Muthén (1998-2015). Mplus User's Guide (seventh Edition ed.). Los Angeles: Muthén \& Muthén.

Nicholls, J. G. (1984). Achievement motivation: Conceptions of ability, subjective experience, task choice, and performance. Psychological Review, 91(3), 328-346.

Nitsche, S., Dickhäuser, O., Fasching, M. S., \& Dresel, M. (2013). Teachers' professional goal orientations: Importance for further training and sick leave. Learning and Individual Differences, 23, 272-278.

Nylund, K. L., Asparouhov, T., \& Muthén, B. O. (2007). Deciding on the number of classes in latent class analysis and growth mixture modeling: A Monte Carlo simulation study. Structural Equation Modeling, 14(4), 535-569.

Ohlsson, J. (2013). Team learning: Collective reflection processes in teacher teams. Journal of Workplace Learning, 25(5), 296-309.

Opfer, V. D., \& Pedder, D. (2011). Conceptualizing teacher professional learning. Review of Educational Research, 81(3), 376-407.

Oude Groote Beverborg, A. (2015). Fostering sustained teacher learning. Dissertation: University of Twente, Enschede.

Parker, P. D., Martin, A. J., Colmar, S., \& Liem, G. A. (2012). Teachers' workplace well-being: Exploring a process model of goal orientation, coping behavior, engagement, and burnout. Teaching and Teacher Education, 28(4), 503-513.

Pastor, D. A., Barron, K. E., Miller, B. J., \& Davis, S. L. (2007). A latent profile analysis of college students' achievement goal orientation. Contemporary Educational Psychology, 32(1), 8-47.

Payne, S. C., Youngcourt, S. S., \& Beaubien, J. M. (2007). A meta-analytic examination of the goal orientation nomological net. Journal of Applied Psychology, 92(1), 128-150.

Poortvliet, P. M., Janssen, O., Van Yperen, N. W., \& Van de Vliert, E. (2007). Achievement goals and interpersonal behavior: How mastery and performance goals shape information exchange. Personality and Social Psychology Bulletin, 33(10), 1435-1447.

Pulkka, A.-T., \& Niemivirta, M. (2013). In the eye of the beholder: Do adult students' achievement goal orientation profiles predict their perceptions of instruction and studying? Studies in Educational Evaluation, 39(3), 133-143.

Retelsdorf, J., Butler, R., Streblow, L., \& Schiefele, U. (2010). Teachers' goal orientations for teaching: Associations with instructional practices, interest in teaching, and burnout. Learning and Instruction, 20(1), 30-46.

Richter, D., Kunter, M., Klusmann, U., Lüdtke, O., \& Baumert, J. (2011). Professional development across the teaching career: Teachers' uptake of formal and informal learning opportunities. Teaching and Teacher Education, 27(1), 116-126.

Runhaar, P., Sanders, K., \& Yang, H. (2010). Stimulating teachers' reflection and feedback asking: An interplay of self-efficacy, learning goal orientation, and transformational leadership. Teaching and Teacher Education, 26(5), 1154-1161.

Schiefele, U., \& Schaffner, E. (2015). Teacher interests, mastery goals, and self-efficacy as predictors of instructional practices and student motivation. Contemporary Educational Psychology, 42, 159-171.

Schwinger, M., Steinmayr, R., \& Spinath, B. (2012). Not all roads lead to Rome - Comparing different types of motivational regulation profiles. Learning and Individual Differences, 22(3), 269-279.

Schwinger, M., Steinmayr, R., \& Spinath, B. (2016). Achievement goal profiles in elementary school: Antecedents, consequences, and longitudinal trajectories. Contemporary Educational Psychology, 46, 164-179.

Schwinger, M., \& Wild, E. (2012). Prevalence, stability, and functionality of achievement goal profiles in mathematics from third to seventh grade. Contemporary Educational Psychology, 37(1), 1-13.

Shim, S. S., \& Finch, W. H. (2014). Academic and social achievement goals and early adolescents' adjustment: A latent class approach. Learning and Individual Differences, 30, 98-105.

Skaalvik, E. M., \& Skaalvik, S. (2013). Teachers' perceptions of the school goal structure: Relations with teachers' goal orientations, work engagement, and job satisfaction. International Journal of Educational Research, 62, 199-209. 
Stoll, L., Bolam, R., McMahon, A., Wallace, M., \& Thomas, S. (2006). Professional learning communities: A review of the literature. Journal of Educational Change, 7(4), 221-258.

Tapola, A., \& Niemivirta, M. (2008). The role of achievement goal orientations in students' perceptions of and preferences for classroom environment. British Journal of Educational Psychology, 78(2), 291-312.

Throndsen, I., \& Turmo, A. (2013). Primary mathematics teachers' goal orientations and student achievement. Instructional Science, 41(2), 307-322.

Tuckey, M., Brewer, N., \& Williamson, P. (2002). The influence of motives and goal orientation on feedback seeking. Journal of Occupational and Organizational Psychology, 75(2), 195-216.

Tuominen-Soini, H., Salmela-Aro, K., \& Niemivirta, M. (2008). Achievement goal orientations and subjective well-being: A person-centred analysis. Learning and Instruction, 18(3), 251-266.

Tuominen-Soini, H., Salmela-Aro, K., \& Niemivirta, M. (2011). Stability and change in achievement goal orientations: A person-centered approach. Contemporary Educational Psychology, 36(2), 82-100.

Tuominen-Soini, H., Salmela-Aro, K., \& Niemivirta, M. (2012). Achievement goal orientations and academic wellbeing across the transition to upper secondary education. Learning and Individual Differences, 22(3), 290-305.

Tynjälä, P. (2008). Perspectives into learning at the workplace. Educational Research Review, 3(2), 130-154.

Van Eekelen, I. M., Vermunt, J. D., \& Boshuizen, H. P. A. (2006). Exploring teachers' will to learn. Teaching and Teacher Education, 22(4), 408-423.

Van Offenbeek, M. (2001). Processes and outcomes of team learning. European Journal of Work and Organizational Psychology, 10(3), 303-317.

Van Yperen, N. W. (2006). A novel approach to assessing achievement goals in the context of the $2 \times 2$ framework: Identifying distinct profiles of individuals with different dominant achievement goals. Personality and Social Psychology Bulletin, 32(11), 1432-1445.

Van Yperen, N. W., \& Orehek, E. (2013). Achievement goals in the workplace: Conceptualization, prevalence, profiles, and outcomes. Journal of Economic Psychology, 38, 71-79.

VandeWalle, D. (1997). Development and validation of a work domain goal orientation instrument. Educational and Psychological Measurement, 57(6), 995-1015.

VandeWalle, D. (2004). A goal orientation model of feedback-seeking behavior. Human Resource Management Review, 13(4), 581-604.

Van Woerkom, M., \& Croon, M. (2008). Operationalising critically reflective work behaviour. Personell Review, 37(3), 317-331.

Vangrieken, K., Dochy, F., \& Raes, E. (2016). Team learning in teacher teams: Team entitativity as a bridge between teams-in-theory and teams-in-practice. European Journal of Psychology of Education, 31(3), 275-298.

Wang, J. C. K., Morin, A. J. S., Liu, W. C., \& Chian, L. K. (2016). Predicting physical activity intention and behaviour using achievement goal theory: A person-centred analysis. Psychology of Sport and Exercise, 23, 13-20.

Weiss, A. M., Lurie, N. H., \& MacInnis, D. J. (2008). Listening to strangers: Whose responses are valuable, how valuable are they, and why? Journal of Marketing Research, 45(4), 425-436.

Woehr, D. J., Loignon, A. C., Schmidt, P. B., Loughry, M. L., \& Ohland, M. W. (2015). Justifying aggregation with consensus-based constructs. Organizational Research Methods, 18(4), 704-737.

Wong, S. S. (2004). Distal and local group learning: Performance trade-offs and tensions. Organization Science, 15(6), 645-656.

Zhang, M. J., Law, K. S., \& Lin, B. (2016). You think you are big fish in a small pond? Perceived overqualification, goal orientations, and proactivity at work. Journal of Organizational Behavior, 37(1), 61-84.

Eva Kunst is a PhD Candidate at the Department of Human Resource Studies at Tilburg University, the Netherlands. The focus of her dissertation is on the value of individual differences between teachers for team learning in teacher teams. She received her MSc degree Child Development and Education in 2013 from the University of Amsterdam, the Netherlands.

Marianne van Woerkom is an Associate Professor at the Department of Human Resource Studies, Tilburg University, the Netherlands. Her research area's include learning and development in organizations, teamwork, coaching, and the application of positive psychology (i.e. a focus on strengths) in organizations.

Rob F. Poell is a professor of human resource development (HRD) in the Department of Human Resource Studies at Tilburg University, the Netherlands. His core field of expertise within HRD is workplace learning, especially viewed from the employees' perspective. He has published widely in HRD, management, and organization journals. He served as editor-in-chief for Human Resource Development International. 